\title{
Mobile Applications to Fight against COVID-19 Pandemic: The Case of Saudi Arabia
}

\author{
Imdadullah Hidayat-ur-Rehman ${ }^{1}$, Arshad Ahmad ${ }^{2}$, Manzoor Ahmed ${ }^{3}$, Aftab Alam ${ }^{4}$ \\ ${ }^{1}$ MIS Department, CBA, King Saud University, Saudi Arabia \\ ${ }^{2}$ Department of Management, CBA, King Saud University, Saudi Arabia \\ ${ }^{3}$ Department of Quantitative Analysis, CBA, King Saud University, Saudi Arabia \\ ${ }^{4}$ Department of Management Sciences, Abasyn University, Peshawar, Pakistan
}

\begin{abstract}
In order to fight against the COVID-19 pandemic the government of Saudi Arabia launched three mobile applications namely Tetamman, Tabaud \& Tawakkalna to keep the public aware about the corona virus and ensure monitoring of the suspected cases. The objective of this study is to curb the spread of COVID-19 by enhancing social measures and investigate the role of mobile applications in achievement of this objective. Comprehensive review of the role of mobile applications was made and a survey approach was used to evaluate the effectiveness of these applications. Findings of the study indicate that the users perceive that the applications are successful in achievement of the objectives for which these applications were launched. The key performance indicators (KPIs) included in the survey were efficiency, ease of use, satisfaction of users, fulfilment of purpose, usefulness and helpfulness etc. The average number of respondents, who agreed that these applications are performing according to the mentioned KPIs, is $86.6 \%$ for Tetamman, $80.5 \%$ for Tabaud and $90 \%$ for Tawakkalna.

More awareness campaigns are needed so that more people adopt the use of these applications, which could significantly help in identification of new cases
\end{abstract}

DOI: 10.18421/TEM101-09

https://doi.org/10.18421/TEM101-09

Corresponding author: Imdadullah Hidayat-ur-Rehman, MIS Department, CBA, King Saud University, Saudi Arabia. Email: ihidayaturrehman@ksu.edu.sa

Received: 02 September 2020.

Revised: 15 December 2020.

Accepted: 21 December 2020.

Published: 27 February 2021.

(cc) BY-NC-ND (C) 2021 Imdadullah Hidayat-ur-Rehman et al; published by UIKTEN. This work is licensed under the Creative Commons Attribution-NonCommercial-NoDerivs 4.0 License.

The article is published with Open Access at www.temjournal.com and enhance telehealth and teleconsultations. Moreover, the applications should be upgraded for self-triage.

Keywords: Mobile applications, COVID-19, telehealth, health monitoring, contact tracing, virus transmission, crisis management.

\section{Introduction}

The corona virus pandemic (COVID-19) spread in more than 200 countries and about 1,608,648 deaths were confirmed till $14^{\text {th }}$ December 2020 all over the world [24]. Due to unavailability of specific medicine to treat this disease, the governments all over the world are relying on social measures and public health to slow down or stop the expansion of COVID-19 [3]. These measures include physical distancing, contact tracing, prohibiting large gatherings, hand and respiratory hygiene, closures of schools and universities, travels bans and lockdowns of regions [3],[18]. To curb the COVID-19 the Saudi government suspended entries to Makkah and Madinah, imposed curfew across the country, closed all schools, universities, and banned domestic and international travelling [19].

Well developed countries have sophisticated health care system, so they can collapse during epidemics [5],[7]. Intensive IT solutions are needed to undertake significant steps at primary level to diagnose the patients and decrease the extent of contacts to avoid the collapse of secondary and tertiary level [13]. Digital technology novelties can improve efficiency of health system's response during pandemics [3]. Besides the impacts of fast spreading pandemics on different fields of daily life (like working styles, economic, political and social activities), also influences significantly the extant information technology (IT) products and these should be equipped with pandemic characteristics [13]. There is urgency to launch such an adoptable platform that can capture real-time high quality data that can cover the spectrum of subclinical 
presentations and identify discrepancies in diagnosis and treatment [8].

To keep the people aware about the COVID-19 pandemic and to overcome the outbreak different governments launched smartphone applications. For example, the Chinese government launched WeChat and AliPay applications with geotracking and metadata features to designate citizens from low risk to high risk [4]. Singapore used TraceTogether for contact tracing to locate the persons who exposed to infected persons [6]. Likewise, the government of Saudi Arabia launched smartphone applications (namely Tetamman, Tabaud and Tawakkalna) to prevent the spread of corona virus, provide information about the number of corona infections in the kingdom and early detection of corona infections once users show corona virus symptoms. The Saudi Centre for Disease Prevention and Control monitors continuously the COVID-19 outbreak and takes different steps to control the spread of cases by launching awareness and precautionary programs. Due to these concrete steps, the Saudi government successfully overcome the spread of COVID-19 and total recovered cases are 350,792 out of 360,013 confirmed cases till $14^{\text {th }}$ December 2020 [17].

This paper presents the espousal and growth of mobile application as an efficient response to the epidemic spread of COVID-19 through reduction in social distancing and prompt identification of the infected cases. Presently, mobile applications usage is increased, as more people are concerned to update information about COVID-19. The success of such applications depends on the number of users and key performance indicators like efficiency, ease of use, satisfaction of users and fulfilment of the purpose. More will be users, more data is captured and made available for decision-making and more people are benefited. This study attempts to address the following research questions:

Research Qesution1: What is the role of mobile application in controlling the COVID-19 in Saudi Arabia?

Research Qesution2: How the users evaluate these mobile applications in terms of the services provided by these applications?

Research Qesution3: What are the challenges due to which the effectiveness of these applications is reduced?

This study contributes to theory by highlighting the strengths and limitations of mobile applications used in Saudi Arabia to curb the spread of COVID19, and thus open the doors for future research opportunities. The practitioners can use findings of the study for further improvement of the applications about contact tracing, telehealth monitoring and teleconsultations.
Remaining of the paper is organised as follows. First, the role of mobile applications in monitoring and controlling the COVID-19 generally and in the context of Saudi Arabia is presented. Second, the methodology used by this study is discussed briefly. Third, discussion about results, theoretical \& practical implications, challenges, limitation and future research avenues are presented. Conclusion is presented at the end.

\section{The Role of Mobile Applications in Monitoring and Controlling the COVID-19}

Mobile Applications are used for effective collection, flow and exchange of data within the network. Citizens, health workers, social workers and other officials are interconnected to monitor the pandemic and improve decision making. For effective monitoring of the COVID-19, identification of the accurate locations of the infected people is required. Mobile applications can provide information about the population and their mobility which can be used to understand COVID-19 tendencies and respond accordingly [21]. The patient's data can be sent directly to healthcare monitoring entities through telehealth technologies [1]. Such information is helpful in contact tracing, cluster identification and observation of quarantine.

Digital contact tracing accelerates the process of identification of the persons who have come in close contact with the infectious ones [2]. Collecting data from a large population can be helpful in cluster identification [10]. Real time reporting of the symptoms and recovery should be properly conveyed to the health professionals and controllers so that quarantine period can be improved [20].

During lockdown periods, access of the patients to the hospitals becomes difficult. For assistance of such patients many hospitals have introduced telemedicine services that provide remote consultation and advice [11]. Low mood depression has been acknowledged due to self-isolation and lockdowns. Mobile applications are helpful for counselling on mental health and thus provide support to patients [11]. During this COVID-19 pandemic, these medical mobile applications are helpful in remote timely advices, clinical evaluations, prescriptions and monitoring of patients remotely [11]. The healthcare professionals are at high risk for COVID-19 infection [23]. The mobile digital health technology has the capability to reduce the transmission of corona virus by minimising the direct interface between the healthcare professionals and patients [1]. Figure 1 depicts the main features of mobile applications to curb the spread of COVID-19. 


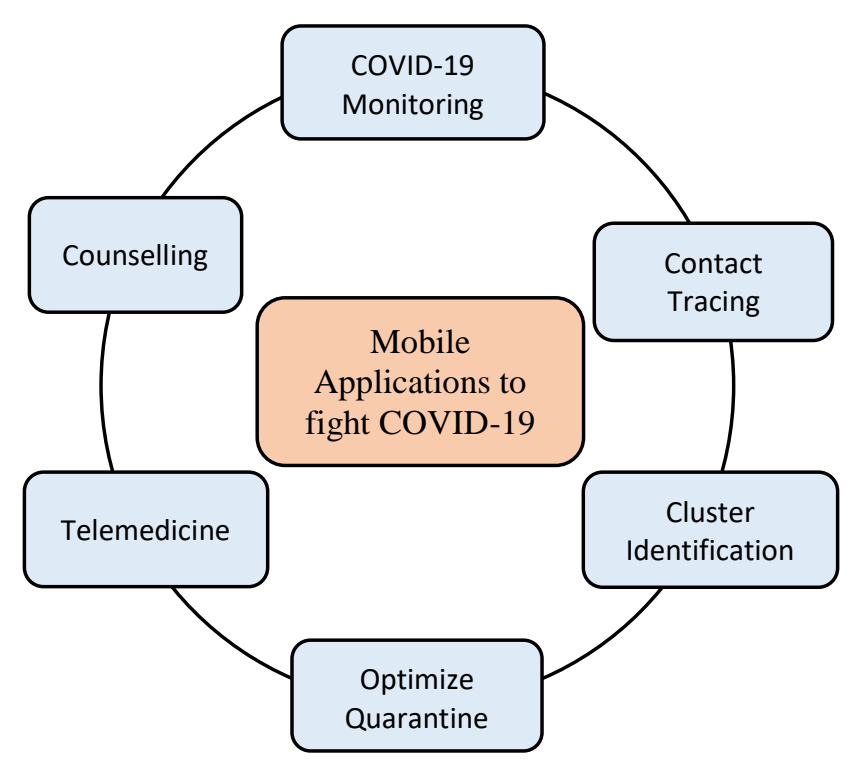

Figure 1. Mobile Applications features to fight COVID-19

\section{Mobile Applications Launched by Saudi Government to Curb the COVID-19 Pandemic}

Investing digital infrastructure is part of a longterm development plan enunciated in Saudi Government's Vision 2030. Deployment of 5G networks is continued to enhance the digital infrastructure. During, the COVID-19 pandemic, $94 \%$ of the staff is able to continue work from home. The Saudi government has shown digital agility to address COVID-19 pandemic and has strengthened its national resilience [25].

The Saudi Ministry of Health $(\mathrm{MOH})$ launched ehealth and m-health programs to control the pandemic. The MOH issued COVID-19 Prevention Guidelines in nineteen different languages so that the citizens and residents will be able to adopt the preventive measures [16]. To keep the citizens and residents fully aware about the COVID-19, the $\mathrm{MOH}$ launched awareness through the web [15]. As part of the m-health program, the MOH Saudi Arabia launched different mobile applications to monitor the COVID-19 infections and to curb its spread. These applications are available free for download on both Google Play and Apple Store. Descriptions of these applications are given below:

\subsection{Tetamman Application}

The MOH launched mobile application with the name Tetamman (Tetamman means rest assured) to prevent the COVID-19 and curb its spread. The aim of the application is to provide protection and healthcare to self-isolating citizens and residents who are in quarantine, and thus to enhance their recovery procedures [14]. The services provided by this application include results of medical examinations, epidemiological investigation, follow-up of health status on daily basis, communication with 937 and updating data about those who remained in close contact with confirmed infected cases. The users can make reservation of an appointment for corona virus examination and get necessary medical assistance.

\subsection{Tabaud (Distancing) Application}

This application has been launched by the Saudi Data \& Artificial Intelligence Authority (SDAIA). The health standards were approved by the $\mathrm{MOH}$ on which this application was developed. The goal of the application is to involve individuals in controlling the corona outbreak and reduce it span [22]. The Tabaud application notifies to users about the infected persons if they were in contact with them. When the application detects a registered infected person, it sends notification to the user so that the user can request direct health support from $\mathrm{MOH}$.

\subsection{Tawakkalna Application}

The Tawakkalna application has been launched by the SDAIA to support the Saudi government's effort to counter the spread of COVID-19. The aim of this application is to enable the issuance of movement e-permits during the curfew periods for employees working in government and private sector and other individuals. This application helps in automating the transactions between all relevant parties like health, security, private entities and individuals to mitigate the economic, social and health impacts that may result from implementation of lockdowns and other policies employed to reduce the spread of COVID-19 [22]. The Tawakkalna application is equipped with the following features:

a. Request movement permits electronically for necessary supplies during curfew periods.

b. The government and private sector entities (like hospitals, pharmacies, catering companies and other important entities) can submit their workers permits electronically so that their workers can move easily from and to their workplace during curfew periods.

c. It responds to frequent health related questions raised by users.

d. The users can report suspected cases so that immediate medical assistance can be provided to users and to stop the spread of infection.

e. Through the application, the users can show the QR code of their e-permit to the security man to speed up the process of permit inspection and enable continuity of traffic.

f. It provides reviews on latest health news.

g. It facilitates the users to apply for e-permit of their private driver.

h. It displays user's medical appointments. 


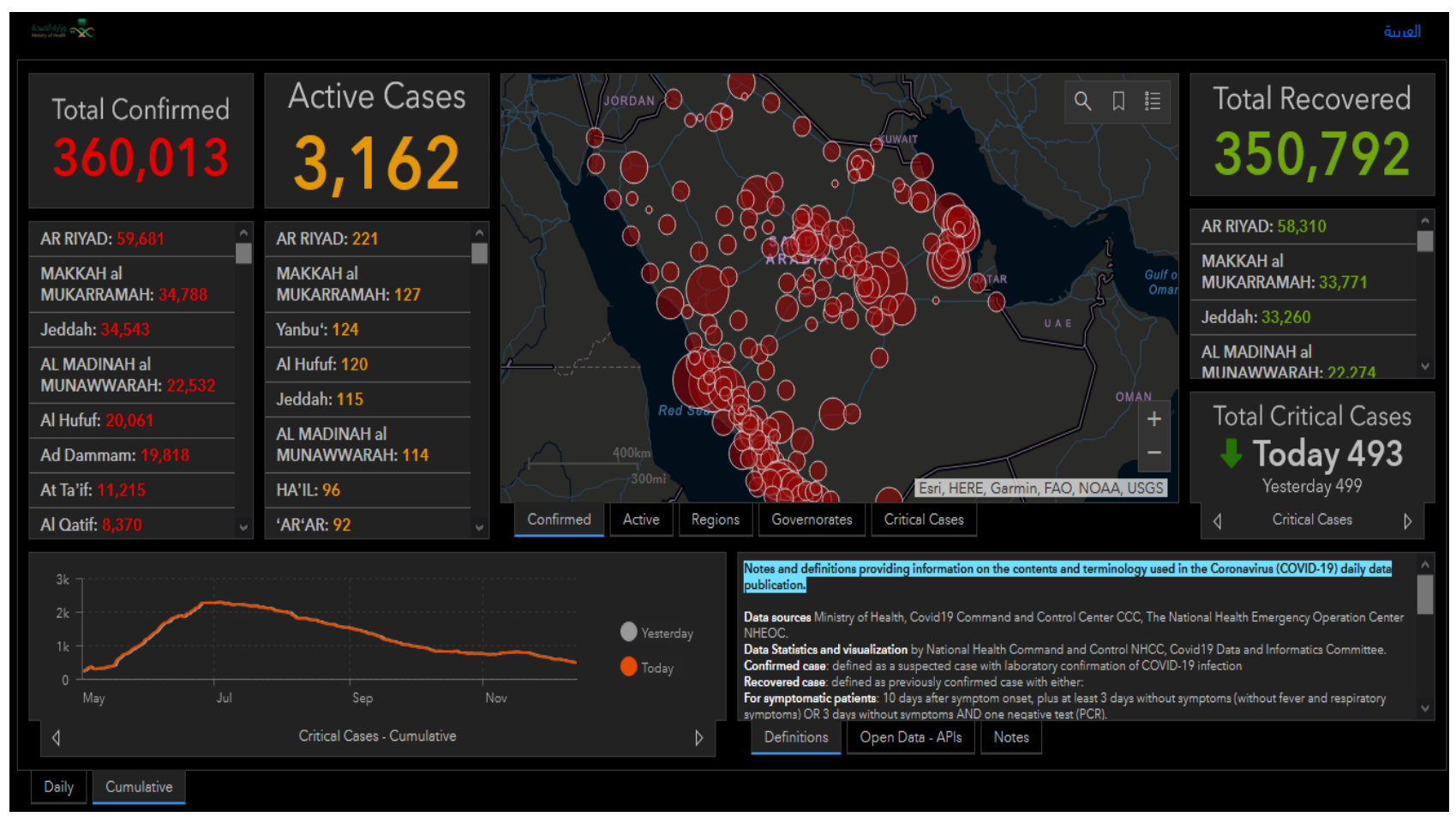

Figure 2. COVID-19 Dashboard: Saudi Arabia (Downloaded from [17])

i. The users can apply for one-hour jogging permits.

j. The application allows the users to apply for emergency medical permits. The issued permit includes patient's companion.

k. The students can apply for student permit if they

\section{Methodology}

To evaluate the performance of the three mobile applications (described in Section 3), survey method was used. The survey contained questions based on the efficiency, ease of use, user satisfaction level, fulfilment of application's purpose and other main features of the application. For this purpose, an online questionnaire was distributed amongst citizens and expatriates in Saudi Arabia. Total 223 responses were received and the response rate was $4.3 \%$. A screening question was added in the start asking: "Do you use any one or more of these applications? 1. Tetamman App, 2. Tabaud App, 3. Tawakkalna App?", all in order to ensure that the feedback should be received only from those respondents who are using one or more applications from the mentioned applications. Eight responses were discarded, as they were using none of these applications. Keeping in view that every respondent may not be user of each of these applications, screening question was added at the beginning of each section of the questionnaire to ask whether they use the application. Table 1 lists the demographics of the respondents. Questions have an examination. They can apply for driver's permit if needed.

below illustrates COVID Dashboard (Saudi Arabia). The dashboard presents up-to-date COVID19 information. This feature is available in other two applications also.

included in the survey about the three applications are listed in Appendix-A:

Table 1. Demographic Information of the Sample

\begin{tabular}{|l|l|c|}
\hline \multirow{2}{*}{ Item } & Characteristics & $\begin{array}{c}\text { No. of responses } \\
(\mathbf{n = 2 2 3})\end{array}$ \\
\hline \multirow{2}{*}{ Nationality } & Saudi Nationals & 123 \\
\cline { 2 - 3 } & Expatriates & 100 \\
\hline \multirow{2}{*}{$\begin{array}{l}\text { Employment } \\
\text { category }\end{array}$} & Health Professionals & 45 \\
\cline { 2 - 3 } $\begin{array}{l}\text { Users of } \\
\text { Mobile } \\
\text { Applications }\end{array}$ & Security officials & 13 \\
\cline { 2 - 3 } & Others & 165 \\
\cline { 2 - 3 } & Tetamman & 174 \\
\cline { 2 - 3 } & Tabaud & 190 \\
\hline
\end{tabular}

\section{Discussion of the Results}

The government of Saudi Arabia succeeded in controlling the COVID-19 in a very short time and the use of digital technologies played a vital role which was appreciated by World Bank [25]. The usage and popularity of the mobile applications is evident from Google Play number of downloads and content rating until December 14, 2020: Tawakkalna (Downloads: 1,000,000+, Content Rating: 4.3), Tetamman (Downloads: 1,000,000+, Content Rating: 3.5), and Tabaud (Downloads: 1,000,000+, Content 
Rating: 4.3). During curfew periods, the individuals, government and private entities were benefited from e-permit facility and were able to continue urgent supplies and deal other emergencies. The public is being updated with the latest news about the pandemic and necessary precautions.
The applications are providing services about medical examinations, self-isolation and quarantine management Figure 3, Figure 4, and Figure 5 summarise the responses received from the users that show their satisfaction with the use of these applications. .

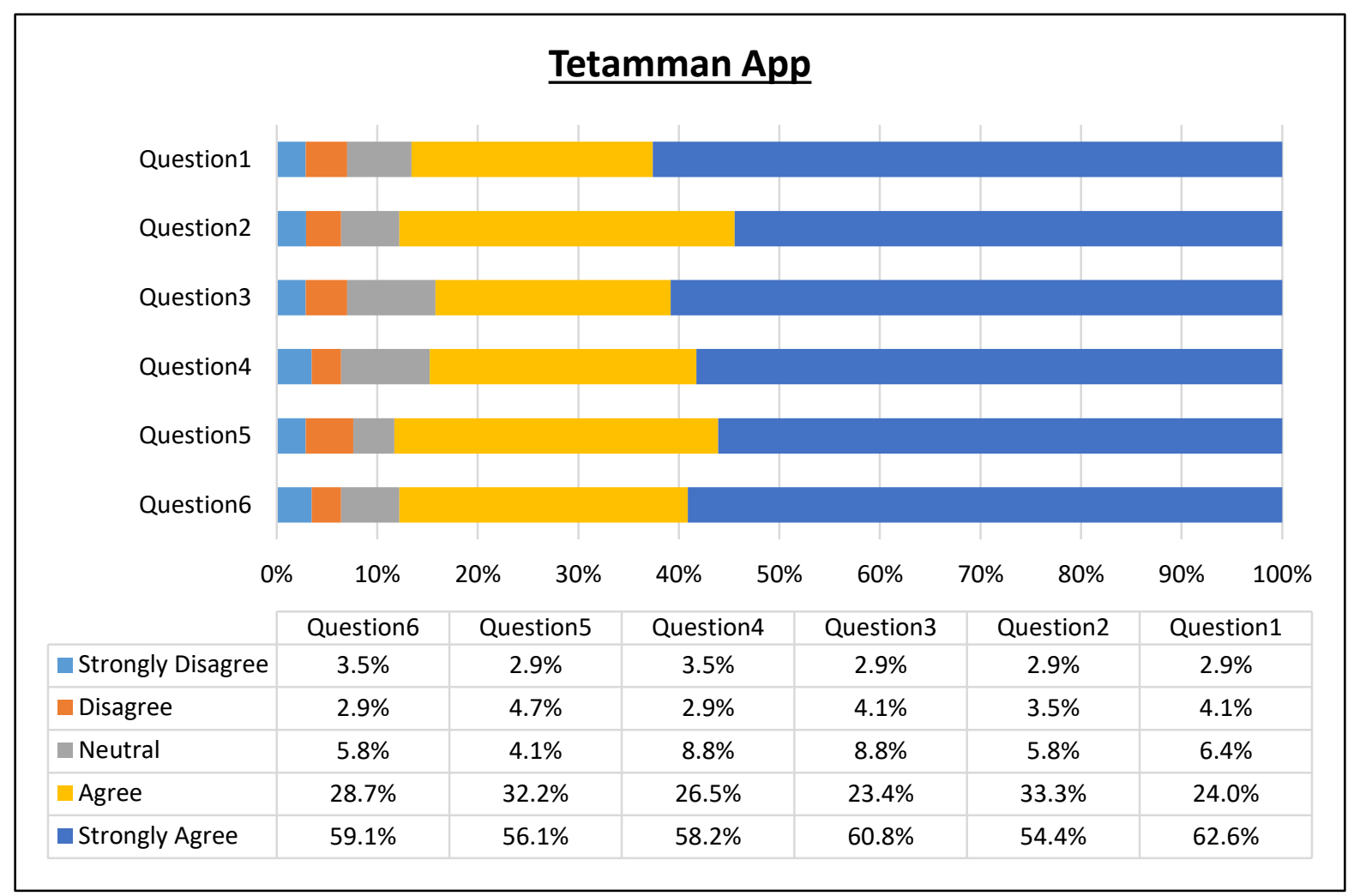

Figure 3. Responses about Tetamman Application

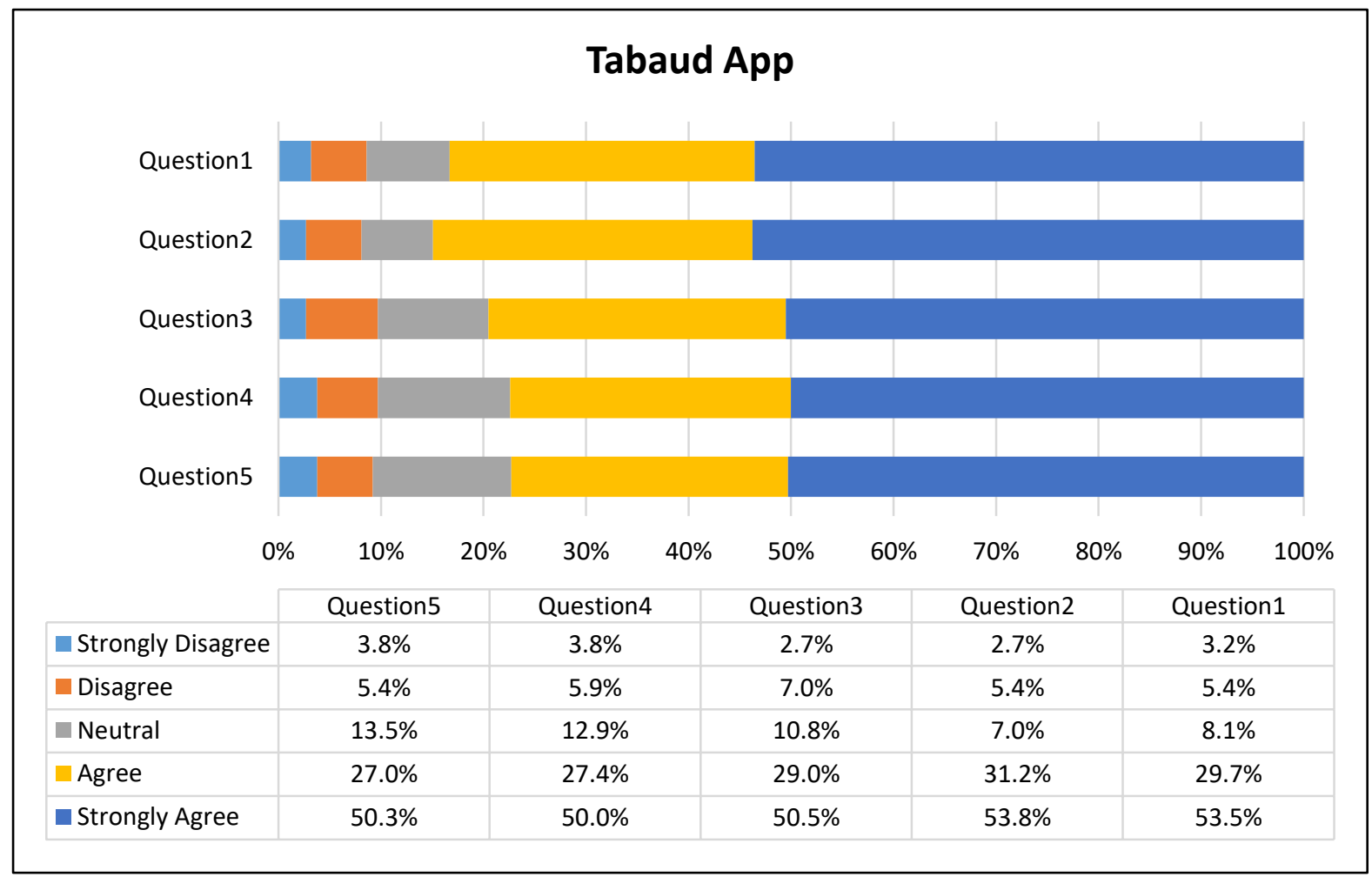

Figure 4. Responses about Tabaud Application 


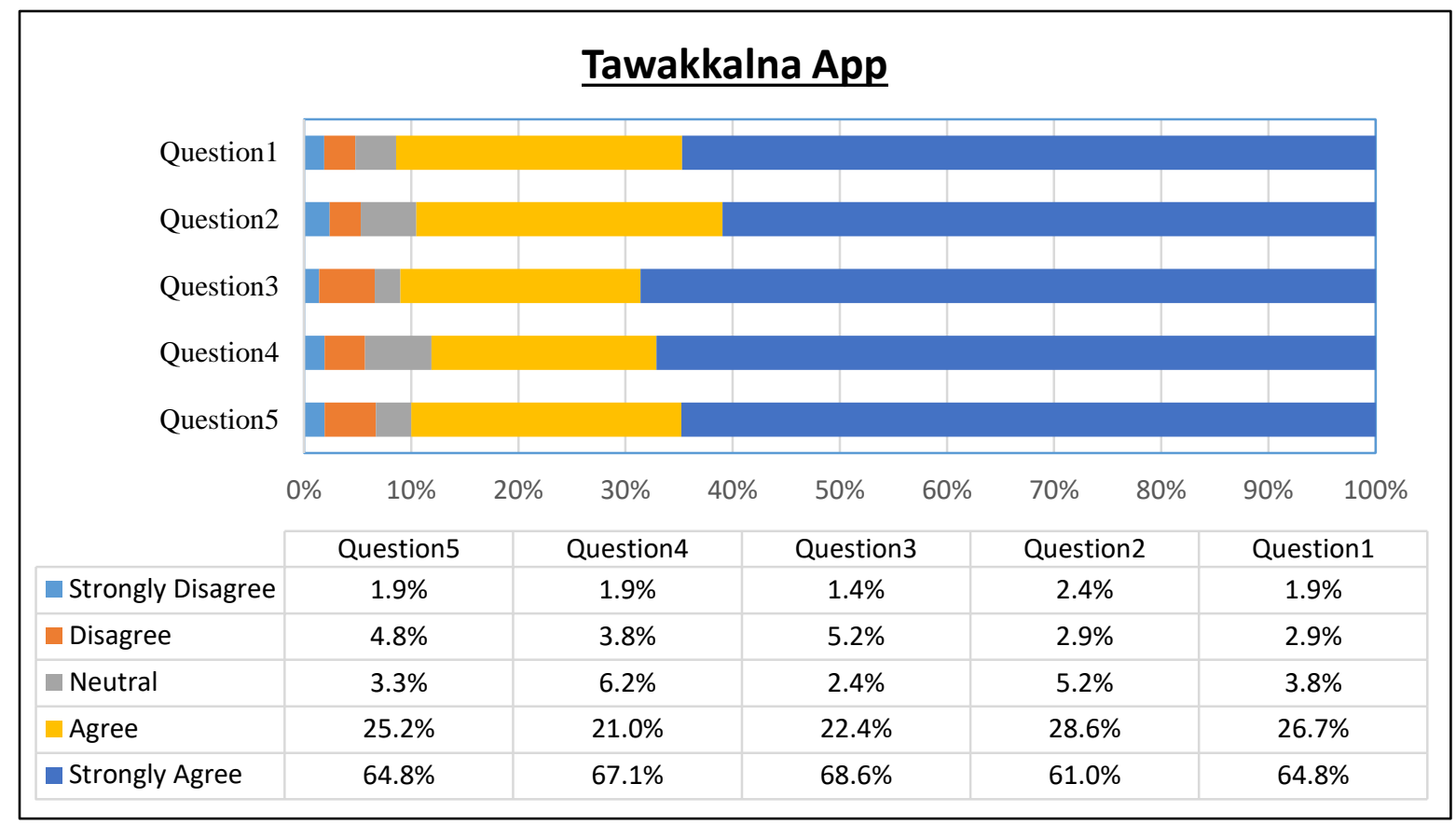

Figure 5. Responses about Tawakkalna Application

Six questions were asked in the survey about Tetamman application. Question 1 is regarding the efficiency of the application and $86.6 \%$ users agree that the application is efficient and helpful. The second question is related to the ease of use and $87.7 \%$ respondents agree that it is easy to use. Next question is about their satisfaction with the use of the application. $84.2 \%$ of the respondents showed their satisfaction. Fourth question asked whether the application fulfils the purpose for which it has been launched. $84.7 \%$ agree that the purpose is fulfilled by the application. Fifth question asked whether the application helped in seeking medical assistance from $\mathrm{MOH} .88 .3 \%$ of the users agree that the application helps in seeking assistance. The last question asked whether the application is helpful in reservations of appointment for COVID-19 test. $87.8 \%$ of the respondents agreed that the application is helpful in making reservation for COVID-19 test. These results indicate the confidence and perceptions of the users about the usage of the application.

The survey contained five questions about Tabaud application. $83.2 \%$ of the respondents agreed that Tabaud application is efficient and helpful. 84.9\% users consider the application easy to use, $79.5 \%$ are satisfied with the usage of the application, $77.4 \%$ agreed that the application fulfils the purpose of its launch and $77.3 \%$ agreed that the application is directing the users to isolate if they are exposed to any person with registered corona infection case. Our findings show that the application's performance is good and it is popular amongst the citizens and expatriates in Saudi Arabia.
There were six questions in our survey about the Tawakkalna application. The first three questions were regarding the efficiency, ease of use and users' satisfaction. The number of respondents who agreed about these three KPIs is $91.5 \%, 89.6 \%$ and $91 \%$ respectively. The fourth question asked was whether they used the application for issuance of e-permit and the issuance process was satisfactory. $88.1 \%$ of the respondents mentioned that they have used the application for issuance of permits and they are satisfied with the issuance process. The fifth question was whether the application responded promptly. $90 \%$ of the users agreed that the application response was prompt. The last question asked was whether they used the application for reporting of COVID-19 cases? 32.9\% responded 'Yes' that means that 32.9\% of respondents have used Tawakkalna application successfully to report new corona cases. This is another indicator of the accomplishment of the Tawakkalna Application.

The role of such mobile applications is important in telehealth and teleconsultations. During pandemics, sending alerts and faster tracking is needed to ensure the safety of people [20]. Without human interaction, data is collected which is helpful for apposite decision making [26]. The captured data can be used for cluster identifications, monitoring of the patients for the pandemic disease and other diseases like heart rate, blood pressure, cardiovascular disease, glucometer and other activities that need personalized attention. The above findings indicate the success of the three mentioned applications in providing telehealth services to the 
public and capturing valuable data, which can be used for prompt and accurate decision-making.

\subsection{Theoretical and Practical Implications}

This study investigated the role of mobile applications in curbing the spread of COVID pandemic in Saudi Arabia. For this purpose, survey procedure was adopted to seek the feedback of users for evaluation of the applications. Discussion on survey results and challenges faced in the success of these applications are presented. This study opens doors for future research avenues about the development and improvement of mobile applications for contact tracing, telehealth and teleconsultation. Academicians can extend this study for comparisons of telehealth applications between developing and developed countries. The areas uncovered by this study can also be addressed by future research. The IT practitioners can be benefited from such research studies to take measures to overcome challenges faced in the widespread adoption of such applications so that these applications can be used effectively in the current and future epidemics.

\subsection{Challenges}

Despite the importance and popularity of these applications, their use is not widespread and effectiveness of these applications is limited.

\subsubsection{Awareness of public}

The public awareness about the availability and usefulness of mobile applications is an important factor. Anyone will use mobile application if he/she is aware of the service. For this purpose, the government needs to launch awareness and motivational programs so that the public come to know about usefulness of the applications and they are attracted to use it. Effective results can be produced only if more and more people are using the application and it captures effective data for decision-making and analysis.

\subsubsection{Data privacy Concerns}

The individuals are concerned about the privacy of the personal data disclosures or hacking due to which they are reluctant towards the use of such mobile applications through which their personal data is collected [4],[11]. Such privacy concerns limit the usefulness of mobile applications. There should be legal regulations protection of the individuals' data.

\subsubsection{Limitation of Identification of Contacts}

The application will identify the infected person only if the exposed and the infected persons are nearer to each other and both are using the same application [12]. For more distances between the infected person and the exposed person, effectiveness of the application is reduced. Launching awareness programs will enhance the effectiveness as more people will be attracted to adopt the applications and identification of the exposed and the infected persons will be easier. Moreover, when the same application is used by a large number of population, there will be more probability that an application on a mobile will find another mobile with the same application nearby and thus detection of the exposed and the infected persons will be achievable.

\subsection{Limitations and Future Research Avenues}

Although this study investigated the role of mobile applications in controlling the COVID-19 pandemic in Saudi Arabia and provided insights about the phenomenon, there are some limitations associated with the study. Addressing these limitations will provide opportunities for further research. First, the scope of this study is limited to Saudi Arabia; future research may explore insights on the use of mobile applications during pandemics for comparisons of different countries. Second, the study has not considered all the metrics about the applications; future research may use Google Analytics or other analytic tool to provide in-depth insights. Third, the study did not collect the captured data through these mobile applications. Further research may collect and analyse the data captured by these applications. Fourth, due to lockdowns and social distancing, this study carried out online survey. Further studies may conduct face-to-face interviews, which may provide deeper insights about the phenomenon. Fifth, individuals' knowledge, experience and perceptions may be different over different periods of time; future research can address this issue by conducting longitudinal studies. Sixth, research groups comprising of health practitioners and information technology researchers can extend this study for conducting research about telehealth and teleconsultation.

\section{Conclusion}

The corona virus pandemic can continue for long time and more mortality rates are expected [13]. Presently, the possible prevention is isolation, quarantine, contact tracing, social distancing and other hygienic measures [9]. Keeping in view the importance of mobile technology, the government of 
Saudi Arabia launched three mobile applications to fight the COVID-19 pandemic. This study presented explorations about the role and features of these applications. However, more work is needed to present analysis of the captured data so that more improvements can be introduced. During COVID-19 if the patients are in critical conditions, the quick actions are based on the proposed triage [13]. The applications should be upgraded for self-triage. More awareness campaigns are needed so that more people are attracted towards the use of these applications, which could significantly help in identification of new cases and enhance telehealth and teleconsultations.

\section{Acknowledgement}

The authors are thankful to the Deanship of Scientific Research at King Saud University represented by the Research Centre in the College of Business Administration for financially supporting this research.

\section{References}

[1]. Alwashmi, M. F. (2020). The use of digital health in the detection and management of COVID19. International Journal of Environmental Research and Public Health, 17(8), 2906.

https://doi.org/10.3390/ijerph17082906

[2]. Dar, A. B., Lone, A. H., Zahoor, S., Khan, A. A., \& Naaz, R. (2020). Applicability of mobile contact tracing in fighting pandemic (covid-19): Issues, challenges and solutions. Computer Science Review, 100307.

[3]. Bassi, A., Arfin, S., John, O., \& Jha, V. (2020). An overview of mobile applications (apps) to support the coronavirus disease-2019 response in India. The Indian Journal of Medical Research. https://doi.org/10.4103/ijmr.ijmr_1200_20

[4]. Behar, J. A., Liu, C., Tsutsui, K., Corino, V. D., Singh, J., Pimentel, M. A., ... \& Osipov, M. (2020). Remote health monitoring in the time of COVID19. arXiv preprint arXiv:2005.08537.

[5]. Boccia, S., Ricciardi, W., \& Ioannidis, J. P. (2020). What other countries can learn from Italy during the COVID-19 pandemic. JAMA internal medicine. https://doi.org/10.1001/jamainternmed.2020.1447

[6]. Cho, H., Ippolito, D., \& Yu, Y. W. (2020). Contact tracing mobile apps for COVID-19: Privacy considerations and related trade-offs. arXiv preprint arXiv:2003.11511. Retrieved July 14, 2020, from http://arxiv.org/abs/2003.11511.

[7]. European Centre for Disease Prevention and Control. (2020). COVID-19 situation update worldwide, as of week 53 2020. Retrieved from:

https://www.ecdc.europa.eu/en/geographicaldistribution-2019-ncov-cases [accessed: 18 July 2020].

[8]. Drew, D. A., Nguyen, L. H., Steves, C. J., Menni, C., Freydin, M., Varsavsky, T., ... \& Spector, T. D. (2020). Rapid implementation of mobile technology for real-time epidemiology of COVID-19. Science. https://doi.org/10.1126/science.abc0473
[9]. Ferretti, L., Wymant, C., Kendall, M., Zhao, L., Nurtay, A., Abeler-Dörner, L., ... \& Fraser, C. (2020). Quantifying SARS-CoV-2 transmission suggests epidemic control with digital contact tracing. Science, 368(6491). https://doi.org/10.1126/science.abb6936

[10]. Inn, T. L. (2020). Smart city technologies take on COVID-19. World Health. Retrieved from: https://penanginstitute.org/wpcontent/uploads/2020/03/27 03 2020_TLI_downloa d.pdf [accessed: 15 July 2020].

[11]. Iyengar, K., Upadhyaya, G. K., Vaishya, R., \& Jain, V. (2020). COVID-19 and applications of smartphone technology in the current pandemic. Diabetes \& Metabolic Syndrome, 14(5), 733-737. https://doi.org/10.1016/j.dsx.2020.05.033

[12]. Kleinman, R. A., \& Merkel, C. (2020). Digital contact tracing for COVID-19. Canadian Medical Association Journal, 192(24), E653-E656.

https://doi.org/10.1503/cmaj.200922

[13]. Milenkovic, A., Jankovic, D., \& Rajkovic, P. (2020). Extensions and adaptations of existing medical information system in order to reduce social contacts during COVID-19 pandemic. International journal of medical informatics, 141, 104224.

https://doi.org/https://doi.org/10.1016/j.ijmedinf.202 0.104224

[14]. MOH. (2020). MOH Launches New App (Tetamman) to Prevent COVID-19. Retrieved from:

https://www.moh.gov.sa/en/Ministry/MediaCenter/N ews/Pages/News-2020-04-11-004.aspx

[accessed: 19 July 2020].

[15]. MOH. (2020). Novel Coronavirus (COVID-19), Retrieved from:

https://www.moh.gov.sa/en/HealthAwareness/Educat ionalContent/PublicHealth/Pages/corona.aspx [accessed: 20 August 2020].

[16]. MOH. (2020b). MOH Prevention Guidlines. Retrieved from:

https://www.moh.gov.sa/en/awarenessplateform/Vari ousTopics/Pages/COIVD-19.aspx [accessed: 20 August 2020].

[17]. MOH, S. A. (2020). COVID19 Dashboard. Retrieved from: https://covid19.moh.gov.sa/ [accessed: 25 August 2020].

[18]. Oliver, N., Lepri, B., Sterly, H., Lambiotte, R., Deletaille, S., De Nadai, M., ... \& Colizza, V. (2020). Mobile phone data for informing public health actions across the COVID-19 pandemic life cycle. https://doi.org/10.1126/sciadv.abc0764

[19]. Perveen, S., Orfali, R., Azam, M. S. U., Aati, H. Y., Bukhari, K., Bukhari, S. I., \& Al-Taweel, A. (2020). Coronavirus nCOVID-19: A pandemic disease and the Saudi precautions. Saudi Pharmaceutical Journal: SPJ: the Official Publication of the Saudi Pharmaceutical Society, 28(7), 888-897. https://doi.org/https://doi.org/10.1016/j.jsps.2020.06. 006

[20]. Singh, R. P., Javaid, M., Haleem, A., \& Suman, R. (2020). Internet of things (IoT) applications to fight against COVID-19 pandemic. Diabetes \& Metabolic Syndrome: Clinical Research \& Reviews, 14(4), 521524. 
[21]. Public health matter. (2020). Coronavirus (COVID19): Using data to track the virus, Retrieved from: https://publichealthmatters.blog.gov.uk/2020/04/23/co ronavirus-covid-19-using-data-to-track-the-virus/ [accessed: 23 August 2020].

[22]. SDAIA. (2020). Saudi Data \& Artificial Intelligence Authority. Retrieved from: https://sdaia.gov.sa/ [accessed: 14 July 2020].

[23]. Wang, C., Horby, P. W., Hayden, F. G., \& Gao, G. F. (2020). A novel coronavirus outbreak of global health concern. The Lancet, 395(10223), 470-473. https://doi.org/10.1016/S0140-6736(20)30185-9

[24]. WHO. (2020). WHO Coronavirus Disease (COVID19) Dashboard. Retrieved from: https://covid19.who.int/ [accessed: 14 July 2020].

[25]. Worldbank. (2020). In Saudi Arabia, investments in digital infrastructure are paying off. Retrieved from: https://blogs.worldbank.org/digital-

development/saudi-arabia-investments-digitalinfrastructure-are-paying [accessed: 10 July 2020].

[26]. Zheng, S. Q., Yang, L., Zhou, P. X., Li, H. B., Liu, F., \& Zhao, R. S. (2020). Recommendations and guidance for providing pharmaceutical care services during COVID-19 pandemic: a China perspective. Research in social and administrative pharmacy.

https://doi.org/https://doi.org/10.1016/j.sapharm.202 0.03 .012

\section{Appendix-A. Survey Questions about Tetamman, Tabaud \& Tawakkalna Applications}

\begin{tabular}{|c|c|c|}
\hline $\begin{array}{l}\text { Mobile } \\
\text { App. }\end{array}$ & & Questions \\
\hline \multirow{6}{*}{ 惡 } & Q1 & $\begin{array}{l}\text { Is Tetamman App efficient and helpful? } \\
\text { On a scale of } 1 \text { to } 5 \text {, rate the efficiency } \\
\text { of the App. }\end{array}$ \\
\hline & Q2 & $\begin{array}{l}\text { Is Tetamman App easy to use? On a } \\
\text { scale of } 1 \text { to } 5 \text {, rate the ease of use of the } \\
\text { App. }\end{array}$ \\
\hline & Q3 & $\begin{array}{l}\text { Are you satisfied with performance of } \\
\text { the App? On a scale of } 1 \text { to 5, rate your } \\
\text { satisfaction level. }\end{array}$ \\
\hline & Q4 & $\begin{array}{l}\text { Does the app fulfil the purpose for which } \\
\text { it has been launched? On a scale of } 1 \text { to } \\
5 \text {, rate the fulfilment of the purpose }\end{array}$ \\
\hline & Q5 & $\begin{array}{l}\text { Does the app help in seeking medical } \\
\text { assistance from Ministry of Health? On a } \\
\text { scale of } 1 \text { to } 5 \text {, rate the assistance you } \\
\text { can get from MOH }\end{array}$ \\
\hline & Q6 & $\begin{array}{l}\text { Does the app help in reservation of } \\
\text { appointment for COVID test? On a scale } \\
\text { of } 1 \text { to } 5 \text {, rate the reservation process and } \\
\text { response }\end{array}$ \\
\hline \multirow{5}{*}{ 导 } & Q1 & $\begin{array}{l}\text { Is Tabaud App efficient and helpful? On } \\
\text { a scale of } 1 \text { to } 5 \text {, rate the efficiency of } \\
\text { the App. }\end{array}$ \\
\hline & Q2 & $\begin{array}{l}\text { Is Tabaud App easy to use? On a scale } \\
\text { of } 1 \text { to } 5 \text {, rate the ease of use of the App. }\end{array}$ \\
\hline & Q3 & $\begin{array}{l}\text { Are you satisfied with performance of } \\
\text { the App? On a scale of } 1 \text { to } 5 \text {, rate your } \\
\text { satisfaction level. }\end{array}$ \\
\hline & Q4 & $\begin{array}{l}\text { Does the app fulfil the purpose for which } \\
\text { it has been launched? On a scale of } 1 \text { to } \\
5 \text {, rate the fulfilment of the purpose }\end{array}$ \\
\hline & Q5 & $\begin{array}{l}\text { Does the app direct you to isolate when } \\
\text { you exposed to any person with } \\
\text { registered corona infected case? On a } \\
\text { scale of } 1 \text { to } 5 \text {, rate the isolation } \\
\text { direction given by app }\end{array}$ \\
\hline \multirow{6}{*}{ 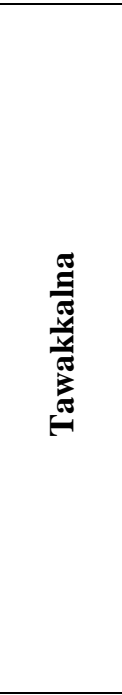 } & Q1 & $\begin{array}{l}\text { Is Tawakkalna App efficient and } \\
\text { helpful? On a scale of } 1 \text { to } 5 \text {, rate the } \\
\text { efficiency of the App. }\end{array}$ \\
\hline & Q2 & $\begin{array}{l}\text { Is Tawakkalna App easy to use? On a } \\
\text { scale of } 1 \text { to } 5 \text {, rate the ease of use of the } \\
\text { App. }\end{array}$ \\
\hline & Q3 & $\begin{array}{l}\text { Are you satisfied with performance of } \\
\text { the App? On a scale of } 1 \text { to } 5 \text {, rate your } \\
\text { satisfaction level. }\end{array}$ \\
\hline & Q4 & $\begin{array}{l}\text { Did you issue any e-permit during } \\
\text { curfew periods? On a scale of } 1 \text { to } 5 \text {, rate } \\
\text { the issuance process of e-permits. }\end{array}$ \\
\hline & Q5 & $\begin{array}{l}\text { Was the App's response faster and well } \\
\text { in time? On a scale of } 1 \text { to } 5 \text {, rate the } \\
\text { App' response. }\end{array}$ \\
\hline & Q6 & $\begin{array}{l}\text { Have you used the App for reporting of } \\
\text { COVID-19 cases? }\end{array}$ \\
\hline
\end{tabular}

